Uche Ezeh, C, Nwankwo, C.F. International Journal of Science Letters (IJSL). 2021. 3(2): 82-96.

https://doi.org/ 10.38058/ijsl.893931

Review

\title{
Assessment of tools for sustainability appraisal of buildings/building groups
}

\author{
Christopher Uche Ezeh ${ }^{1 *}$, Cletus Famous Nwankwo ${ }^{1}$ \\ ${ }^{1}$ Department of Geography, University of Nigeria Nsukka, Nsukka/Niger
}

\begin{abstract}
The construction sector is one of the significant users of energy and natural resources. It was estimated that the sector uses nearly $40 \%$ of the total raw-material inflow to the global economy each year. Based on this fact, the construction sector is an essential contributor to environmental pollution and poses challenges in meeting sustainable development goals. This paper discusses the building assessment tools or models used to assess whether a building meets environmental standards with the view to explore the applications of these tools and their benefits. The paper notes that the environmental assessment models and the assessment itself are worthwhile as it offers several benefits to the society and environment, especially the first among them, the Building Research Establishment Environmental Assessment Method (BREEAM) in the UK. The BREEAM model has created awareness among the stakeholders and has achieved high levels of success. Over 1000 buildings have been assessed in the UK and over 1800 individuals involved as assessors. Thus, it creates jobs in addition to protecting the environment. Mitigation measures are integrated into the certification. It is cost-effective, especially in the long run and more environmentally friendly, unlike the conventional ones. Moreover, efforts should be geared towards harmonising the rating scales and standards across continents or climate regions.
\end{abstract}

Article History Received 10.03.2021 Accepted 01.06.2021

\section{Introduction}

The actions of humans on the environment have impacted it negatively such that environmental quality is compromised and its resources endangered. Anthropogenic activities have contributed immensely to the disruption of climate, freshwater system, ecosystem and forests and have had devastating impacts on local communities, especially in developing regions of the world (Madu and Nwankwo, 2020). The construction sector is one of the significant users of energy and natural resources. It was estimated that the sector uses nearly

${ }^{1}$ Correspondence: cletus.nwankwo@unn.edu.ng 
$40 \%$ of the total raw-material inflow to the global economy each year (Uttam, 2014). Based on this fact, the construction sector is an essential contributor to environmental pollution and poses challenges in meeting sustainable development goals. Carbon dioxide emission is evident in all the phases of a building's life cycle, from material production through construction to demolition (Uttam, 2014). However, the earth's natural resource base is finite (Rockström et al., 2013), hence the need for the sector to improve its environmental performance (Tam et al., 2006; Uttam, 2014). This implies minimising the negative environmental impacts of its activities and products while still maintaining quality service delivery. Also needed is the preservation of local heritage and access to green space (Uttam, 2014). Such actions are critical as protecting the environment is a global agenda that has remained topical in the twenty-first century (Nwankwo, 2018).

Several critical policies formulated to curb the degradation include but are not limited to green public procurement (GPP) (Haapio and Viitaniemi, 2008), Sustainable public procurement (SPP) and Environmental Impact Assessment (EIA). GPP is "the approach by which public authorities integrate environmental criteria into all stages of their procurement process, thus encouraging the spread of environmental technologies and the development of environmentally sound products by seeking and choosing outcomes and solutions that have the least possible impact on the environment throughout their whole life cycle" (Bouwer et al., 2005). A growing concern on social aspects yielded SPP (McCrudden, 2004) since the social dimension is an aspect of sustainable goals. One of the main objectives of SPP is to achieve blended value via the integration of social, economic and environmental objectives (Williams et al., 2007). EIA is simply a systematic process to identify, predict and evaluate the effects on the environment of proposed actions and projects (Sadler, 2004). An extended sort of EIA is the SEA which aims to integrate the environmental and sustainability consideration in strategic decision-making (Therivel, 2012). A more potent synergy between EIA and GPP has been posited to promote coordination between planning and construction phases (Uttam, 2014). BREEAM is a good example where such linkage has yielded results.

Propelled by meeting sustainable development goals, the building sectors started putting up measures to mitigate environmental impacts (Haapio and Viitaniemi, 2008; Ahmad and Thaheem, 2018). Thus, sustainability has increasingly become central to building development (Happio, 2012; Kawakubo et al., 2018). Another important driver was the growing demand for environmentally sound products and services which was not unconnected 
to the public policy to mitigating environmental impacts and achieving sustainability. Hence, the yardstick became the quality of building performance. This was difficult to define, as investors are interested in economic performance while tenants are interested in health and comfort aspects (Haapio and Viitaniemi, 2008). These were instrumental in the emergence of building assessment tools. This paper discusses the building assessment tools with the view to keep abreast scholars and planners with the applications of these tools and their benefits. The following section discusses the building assessment tools and applications before the conclusion is presented.

\section{Building Assessment Tools and Applications}

Various indicators and associated tools were developed to meet different interest groups. The first of these was the Building Research Establishment Environmental Assessment Method (BREEAM) in the UK in the 1990s (Grace, 2000; Lee, 2013; Ilhan and Yaman, 2016). Many of the tools have gained global recognition and have formed discourse in specific conferences like the Green Building Challenge (GBC) (Haapio and Viitaniemi, 2008). Hitherto, according to Haapio and Viitaniemi (2008), the International Organisation for Standardisation (ISO) was at the forefront of defining standard requirements for environmental assessment of buildings. Efforts to improve the building quality have been on the increase ever since. The European Committee for Standardisation provided a voluntary guide for assessing sustainability aspects of new and existing construction works and products (CEN, 2005 cited by Haapio and Viitaniemi, 2008). Several environmental assessment tools for buildings abound and range in applicability, covering different phases of a building's life cycle and different environmental issues. The tools (Table 1) are developed for different purposes such as research, consulting, decision-making and maintenance (Haapio and Viitaniemi, 2008). The tools used depend on the building type (residential, commercial or office) and its stage of development- whether new or existing. The list is inexhaustible as there are still others like SBAT (South Africa), BEAM (Ireland and Hong Kong) (Calquin 2017; Hui et al., 2017), SBTool (EU) (Larsson, 2015; Bernardi et al., 2017; Atanda and Öztürk, 2020), Rapid Sustainability Assessment (RSAM, Kazakhstan) (Karaca et al., 2020), Building sustainability assessment method (BSAM, Sub-Saharan Africa) (Olawumi et al., 2020), Ecology, Energy saving, Waste reduction and Health (EEWH, Taiwan) (Liu et al., 2019), Gesellschaft fur Nachhaltiges Bauen (DGNB, Germany, Denmark) (Stender and Walter, 2019; Al-Qawasmi et al., 2019). 
Table 1. List of some of the building assessment tools

\begin{tabular}{cc}
\hline Tool & Developer \\
\hline ATHENA $^{\text {TM }}($ EIE $)$ & ATHENA sustainable material Institute Canada \\
BEAT 2002 & Danish Building Research Institute (SBI) Denmark \\
BeCost & VTT Finland \\
BEES 4.0 & US National Institute of Standards and Technology (NIST) \\
BREEAM & Building Research Establishment (BRE) the UK \\
EcoEffect & Royal Institute of Technology (KTH) Sweden \\
EcoPrifile & Norwegian Building Research Institute (NBI) Norway \\
EcoQuantum & IVAM, the Netherlands \\
Envest 2 & Building Research Establishment (BRE) the UK \\
Environmental Status & Association of the Environmental Status of Buildings Sweden \\
Model (Miljostatus) & \\
EQUER & Ecoles des Mines de Paris,Centre d' Energetique et procedes France \\
ESCALE & CTSB and the University of Savoie France \\
LEED & US Green Building Council, USA \\
LEGEP & University of Karlsruhe, Germany \\
PAPOOSE & TRIBU France \\
TEAM & Ecobilan, France \\
CASBEE & Japan \\
BEAM Plus & HongKong modelled from BREEAM \\
ESGB & China modelled from LEED \\
\hline TEAM & ing is a professional LCA tool for evaluating life cycle, environmental and cost profiles of products and technologies, including \\
buildings. It is the only tool here that is not specifically for the environmental assessment of buildings (Haapio and Vitaniemi, 2008; Lee, \\
2013).
\end{tabular}

In recent times, it has progressed from sustainability to Green Building assessment which assesses buildings to learn if they meet the needs of reducing adverse impacts on the environment and the occupants throughout its life cycle (Li et al., 2017; Liu et al., 2019). Thus, a building is only certified green if it meets the following attributes; energy saving, efficiency in water and other resources use; pollution and waste reduction; carbon emission reduction; materials re-use and recycling; renewable energy usage; healthy indoor environment and air quality; use of green and sustainable materials and consideration of biodiversity in building designs (Liu et al., 2019). It has been argued that most of the tools fail to incorporate economic and social aspects (Lopez et al., 2019). Social and economic sustainability assessments have been advocated for residential buildings (Ahmad and Thaheem, 2018; Stender and Walter, 2019) integrated with Building information modelling (Solla et al., 2016). For instance, a collaboration by Danish Building Research Institute integrated social sustainability into the Gesellschaft fur Nachhaltiges Bauen (DGNB) assessment tool (Stender and Walter, 2019). Also, there has been advocacy for a tool to assess heritage and recreational buildings due to their specificity (Raslanas et al., 2016; Al-Sakkaf et al., 2020). Due to the multiplicity and diversity of rating systems in sustainability building 
assessment, Mahmoud et al. (2019) devised a global assessment tool for assessing buildings. However, the limitation here is that there are significant environmental differences among countries, variations in building qualities between developed and developing nations, among other factors. Nevertheless, a harmonised assessment tool at larger scales probably based on similarity of environmental factors or climate is needed. Such a tool will aid comparability of performances (Mahmoud et al., 2019), might minimise costs and enhance the achievement of sustainability in buildings across regions.

\section{Method Applications}

The tools are grouped below based on the kind of buildings they can assess (Table 2) and phases of the life cycle (Table 3). A dot indicates a building type the given tool can assess.

Table 2. Tools and the building types they assess (Haapio and Viitaniemi, 2008)

\begin{tabular}{|c|c|c|c|c|c|c|c|c|c|}
\hline Tools & $\begin{array}{l}\text { Existing } \\
\text { Building }\end{array}$ & $\begin{array}{c}\text { New } \\
\text { building }\end{array}$ & $\begin{array}{c}\text { Refurbishment } \\
\text { of Building }\end{array}$ & $\begin{array}{c}\text { Building } \\
\text { product } \\
\text { component }\end{array}$ & Building & $\begin{array}{c}\text { Residential } \\
\text { building } \\
\text { (Multi- } \\
\text { unit) }\end{array}$ & $\begin{array}{c}\text { Residential } \\
\text { building } \\
\text { (Single } \\
\text { unit) }\end{array}$ & Office & Others \\
\hline \multicolumn{2}{|c|}{ BEES 4.0} & & & $\bullet$ & & & & & \\
\hline \multicolumn{2}{|c|}{ TEAM } & & & $\bullet$ & $\bullet$ & & & & \\
\hline \multicolumn{2}{|c|}{ ATHENA } & $\bullet$ & $\bullet$ & & & $\bullet$ & $\bullet$ & $\bullet$ & $\bullet$ \\
\hline \multicolumn{2}{|c|}{ BEAT 2002} & $\bullet$ & $\bullet$ & $\bullet$ & $\bullet$ & & & & \\
\hline \multicolumn{2}{|c|}{ BeCost } & & & $\bullet$ & $\bullet$ & & & & \\
\hline \multicolumn{2}{|c|}{ EcoQuantum } & & & & $\bullet$ & & $\bullet$ & & \\
\hline \multicolumn{2}{|c|}{ Envest 2} & & & & & & & $\bullet$ & \\
\hline \multicolumn{2}{|c|}{ EQUER } & $\bullet$ & & & & $\bullet$ & • & $\bullet$ & $\bullet$ \\
\hline \multicolumn{2}{|c|}{ LEGEP } & $\bullet$ & & $\bullet$ & & & & & \\
\hline \multicolumn{2}{|c|}{ PAPOOSE } & & & $\bullet$ & $\bullet$ & $\bullet$ & $\bullet$ & $\bullet$ & $\bullet$ \\
\hline \multicolumn{2}{|c|}{ BREEAM } & - & $\bullet$ & & & $\bullet$ & $\bullet$ & $\bullet$ & $\bullet$ \\
\hline \multicolumn{2}{|c|}{ EcoEffect } & $\bullet$ & $\bullet$ & $\bullet$ & & $\bullet$ & & $\bullet$ & $\bullet$ \\
\hline \multicolumn{2}{|c|}{ EcoProfile } & $\bullet$ & & & & $\bullet$ & $\bullet$ & $\bullet$ & $\bullet$ \\
\hline \multicolumn{2}{|c|}{ ESM } & $\bullet$ & & & & $\bullet$ & $\bullet$ & $\bullet$ & \\
\hline \multicolumn{2}{|c|}{ ESCALE } & $\bullet$ & & & & $\bullet$ & $\bullet$ & $\bullet$ & $\bullet$ \\
\hline \multicolumn{2}{|c|}{ LEED } & $\bullet$ & $\bullet$ & & & $\bullet$ & $\bullet$ & $\bullet$ & $\bullet$ \\
\hline
\end{tabular}

Some of the tools can be utilised for product comparisons and an environmental assessment of a whole building. Envest 2 is only applied to assess office buildings (Table 2). 
Table 3. The tools and the life cycle phases of buildings they assess (Haapio and Viitaniemi, 2008)

\begin{tabular}{|c|c|c|c|c|c|c|}
\hline Tools & Production & Construction & Operation & Maintenance & Demolition & Disposal \\
\hline BEES 4.0 & • & & $\cdot$ & • & $\bullet$ & \\
\hline TEAM & $\bullet$ & - & $\bullet$ & $\bullet$ & $\bullet$ & \\
\hline ATHENA & $\bullet$ & $\bullet$ & & $\bullet$ & - & \\
\hline $\begin{array}{c}\text { BEAT } 2002 \\
\text { BeCost }\end{array}$ & $\bullet$ & $\bullet$ & $\bullet$ & $\bullet$ & $\bullet$ & \\
\hline EcoQuantum & $\bullet$ & $\bullet$ & $\bullet$ & $\bullet$ & $\bullet$ & \\
\hline Envest 2 & $\bullet$ & $\bullet$ & $\bullet$ & $\bullet$ & $\bullet$ & \\
\hline EQUER & $\bullet$ & $\bullet$ & $\bullet$ & $\bullet$ & $\bullet$ & \\
\hline LEGEP & & $\bullet$ & $\bullet$ & $\bullet$ & & \\
\hline PAPOOSE & $\bullet$ & & $\bullet$ & $\bullet$ & $\bullet$ & \\
\hline BREEAM & $\bullet$ & $\bullet$ & $\bullet$ & $\bullet$ & $\bullet$ & \\
\hline EcoEffect & $\bullet$ & $\bullet$ & $\bullet$ & $\bullet$ & - & \\
\hline $\begin{array}{c}\text { EcoProfile } \\
\text { ESM }\end{array}$ & & & $\bullet$ & $\bullet$ & & \\
\hline ESCALE & $\bullet$ & - & - & - & & \\
\hline LEED & $\bullet$ & $\bullet$ & $\bullet$ & $\bullet$ & $\bullet$ & 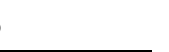 \\
\hline
\end{tabular}

From Table 3 above, most of the tools cover nearly all the phases of the buildings' life cycle. BREEAM is used for all (Table 3), while the Environmental Status Model (ESM) cover none of the phases. From Tables 2 and 3, it is apparent that only a few of the tools cover over $70 \%$ of the building types that can be assessed. These are ATHENA, EcoEffect, BREEAM and LEED. However, in this study, the evaluation will focus on BREEAM since it has higher global usage (BREEAM, 2014); a pioneer tool and the most used in the UK. Therefore, this study will critically review it as the study is literature-based. It is basically to highlight its applications and finally outline its strengths and limitations.

\section{The Building Research Establishment Environment Assessment Method} (BREEAM)

The BREEAM model is built in pursuance of the following aims and objectives (Table 4). It is developed to assess new and existing buildings. The latest version, new construction, can assess diverse kinds of buildings (Tables 1 and 2). Variants of the model like EcoHomes is for refurbished homes, BREEAM schools' assessment Tool replaced in 2008 by BREEAM Education is for assessing educational institutions. Also, the NHS Environmental Tool was introduced in 2008 for assessing healthcare (Islington, 2012). There is a new variant for 
assessing infrastructure. The minimum required standard for BREEAM infrastructure is very good. It employs a scoring system that relates to core areas (Figure 1).

Table 4. Aims and Objectives of BREEAM (BREEAM, 2014)

\begin{tabular}{ll}
\hline \multicolumn{1}{c}{ Aims } & \multicolumn{1}{c}{ Objectives } \\
\hline$-\quad$ Mitigate life cycle impacts of & $\bullet \quad$ Provide market recognition of \\
buildings on the environment & buildings with low environmental impacts \\
$\bullet \quad$ That building be recognised based on & $\bullet \quad$ Ensure best environmental practice is \\
their environmental benefits & part of planning, design construction and \\
- Provide a credible environmental label & operations \\
for buildings & $\bullet \quad$ Define a robust, cost-effective \\
- Stimulate demand for sustainable & performance standard surpassing that \\
buildings and their products & required by regulations \\
& $\begin{array}{l}\text { interest groups in the building sector } \\
\end{array}$ \\
& $\begin{array}{l}\text { innovative, cost-effective solutions that } \\
\text { minimise the environmental impact of }\end{array}$ \\
& buildings \\
\hline
\end{tabular}




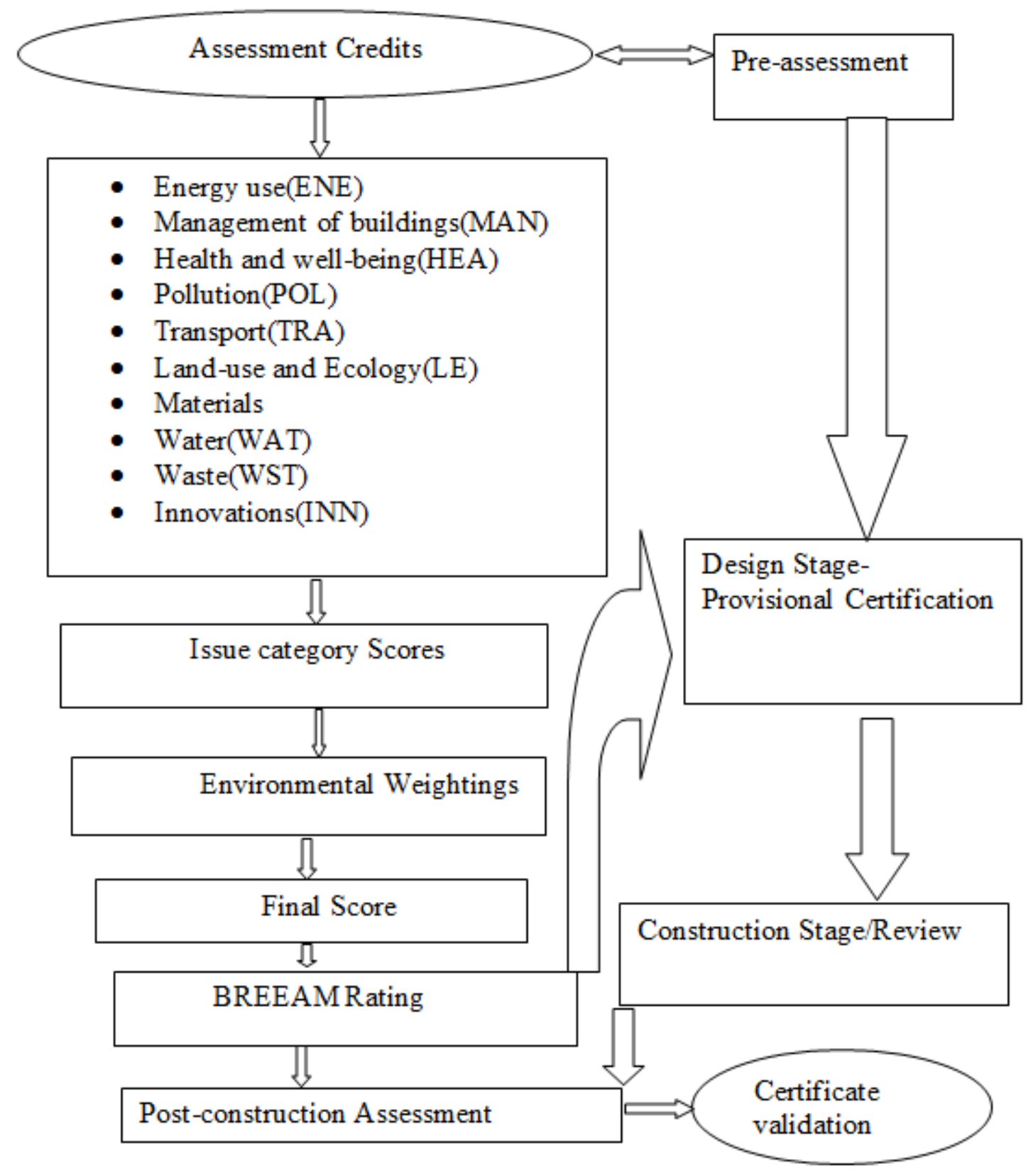

Figure 1. Process of BREEAM rating calculations (Lowe and Watts, 2011; Islington, 2012; BREEAM, 2014; 2016).

The assessment involves awarding credits to each of the areas according to the building's performance against specific criteria (Islington, 2012). The credits are then summed up to produce an overall rating based on a weighting system. Based on this, a certificate is awarded depending on the performance on a scale of PASS (>=30\%), GOOD (>=45\%), VERY GOOD $(>=55 \%)$, EXCELLENT $(>=70 \%$ overall score $)$ and OUTSTANDING $(>=85 \%$ overall score)- a later inclusion. It has a mandatory minimum requirement for water and energy (ISLINGTON, 2012). A certified BREEAM assessor does BREEAM assessment. It involves 
a two-stage process to get a certification. The first is the design stage, followed by the postconstruction stage. This ensures that the plans are executed from design to construction devoid of compromise to the set standards before the provisional certificate issued at the design phase is validated.

However, in 2007, in pursuant of sustainability, EcoHomes was replaced by the Code for Sustainability for assessing new housing in England (ISLINGTON, 2012), but EcoHomes is still used for refurbishment of buildings. This emphasises carbon emissions and energy use from/in homes providing greater regulatory certainty for the builders (ISLINGTON, 2012). It is now mandatory for new homes to undergo a rating based on the code even if the outcome is nil-rating, denoting not assessed (ISLINGTON, 2012). The government aimed to have all homes built to zero carbon standard by 2016 (Table 6) (ISLINGTON, 2012). The scoring for sustainable homes is for nine design categories and their scores (Table 5). Greater emphasis is put on energy, material and health.

Table 5. The BREEAM categories and scores (Parker, 2012; BREEAM, 2014)

\begin{tabular}{c|c|c}
\hline Category & $\begin{array}{c}\text { Score(\%) } \\
\text { Old }\end{array}$ & Score(\%) New \\
\hline Energy & 19 & 15 \\
Health and Well-being & 15 & 15 \\
Materials & 12.5 & 13.5 \\
Management & 12 & 12 \\
Land-use and Ecology & 10 & 10 \\
Pollution & 10 & 10 \\
Transport & 8 & 9 \\
Waste & 7.3 & 8.5 \\
Water & 6 & 7 \\
Total & 100 & 100 \\
Innovation (additional) & - & 10 \\
\hline
\end{tabular}

The ratings have code levels 1 to 6 depending on the building's performance (Table 5). Code level 6 implies zero carbon emissions (Table 6). Level 6 is the goal of the latest BREEAM (Table 6), and greater weight cum importance is assigned to energy and health (Table 5). 
Table 6. Code levels for Sustainable Home rating (Islington, 2012)

\begin{tabular}{cccc}
\hline Code-level & $\begin{array}{c}\text { Minimum reduction in } \\
\text { dwelling CO } \mathbf{C}_{\mathbf{2}} \text { emission rate } \\
\text { over target emission rate } \\
(\boldsymbol{\%})\end{array}$ & $\begin{array}{c}\text { Maximum Water } \\
\text { consumption(1/person/day }\end{array}$ & $\begin{array}{c}\text { Total point } \\
\text { scored on } \\
\text { code (\%) }\end{array}$ \\
\hline 1 & 10 & 120 & 36 \\
2 & 18 & 120 & 48 \\
3 & 25 & 105 & 57 \\
4 & 44 & 105 & 68 \\
5 & 100 & 80 & 84 \\
6 & Zero carbon & 80 & 90 \\
\hline
\end{tabular}

The use of the BREEAM model has many advantages and shortcomings (Table 7).

Table 7. Advantages and disadvantages of BREEAM Model (Lowe and Watts, 2011)

\begin{tabular}{cc}
\hline Pros & Cons \\
Robust & Complicated \\
Detailed & Rigid \\
Famous & Poorly understood \\
Easy to specify & Often poorly specified \\
Independent & Extra cost \\
Tailored to a particular building & A lot of differentiation \\
\hline
\end{tabular}

\section{Examples of Applications - Case studies}

BREEAM was applied to reconstruct the demolished Primary Care Centre on East Gate Road in Driffield that would accommodate GP surgery facilities to serve the community (Lowe and Watts, 2011). The ratings were done and yielded approximately 74\%, which implies excellent. However, the acquisition of green building materials raised the building cost. It was equally applied in constructing a two-storey shopping centre in Italy in 2015 (Jacobs, 2017). It has been used to certify over 260,000 buildings across the building lifecycle and is being applied in over 50 countries (BREEAM, 2014).

\section{Strengths and Limitations}

A lot of benefits accrue from the use of BREEAM for the assessment of buildings. One of the strengths is the actualisation of the aims for its establishment, one of which is to mitigate the life cycle impacts of buildings' environment. It has created awareness and raised consciousness among citizenry stimulating demand for sustainable buildings (Parker, 2012). It 
has ensured that buildings have ratings depending on their performance towards carbon emission reduction (Tables 4 and 5). It has promoted teamwork and dialogue among diverse players in the building sector (Lowe and Watts, 2011). It has led to building efficiency by using energy-efficient fittings and appliances and pollutant-free appliances like chlorofluorocarbon-free air conditioners(Roodman et al., 1995). Some studies have evidence that BREEAM assessment is cost-effective (Lowe and Watts, 2011). For instance, Roodman et al. (1995) indicate that the use of unbaked brick has lowered pollution to 0.2 per cent. They noted a housing development in Dallas, the USA, that slashed utility bills by 450 dollars upon incorporating solar heating.

However, some argue that the cost premium arising from designing a building to meet the BREEAM rating standards can be excessive (Lowe and Watts, 2011). This rising cost is due to the higher cost of acquiring the green building materials introduced to replace the noncompliant materials (Lowe and Watts, 2011). Nevertheless, it is still more cost-effective when considered in the long run. Furthermore, significant weakness is the non-existence of standard measurement scales. That is, there is no logical basis for assigning the maximum number of points for each case. There is an element of subjectivity in the weighting system. Thus, there is the need for a uniform or consistent scalar system which will enhance comprehension and enable data handling (Cole, 1998). This is complicated by the broad scope of data for assessment and which weights are assigned (Kajikawa et al., 2011). These criteria include a mixture of quantitative and qualitative data, and as such, ambiguity may arise in handling them.

\section{Discussion and Suggestions}

There are substantial variations among the various building assessment tools, which vary according to scope, rating scales and performance (Kajikawa et al., 2011; Mahmoud et al., 2019). There are also variations based on the building types assessed, age or life cycle. Additionally, some of the tools focus on the energy demands and consumption or total environmental quality that focus on the ecological and socio-economic aspects (Berardi, 2012; Mahmoud et al., 2019). Green building assessment tools address several issues such as recycling materials, conservation of water and energy, healthy air and temperature, illumination of the indoor environment, rainwater harvesting and recycling, reduction of carbon emission and below-ground reservoir (Liu et al., 2019). However, the use of the tools 
and the factors considered is dependent on the type, size and use to which the building is to be put.

Furthermore, Al-Qawasmi (2019) and Braulio-Gonzalo and Bovea (2020) reveal marked variations and inhomogeneity in the breadth and length of coverage of attributes. As such, out of the dimensions of sustainability, the social aspect gets the least representative coverage (Al-Qawasmi 2019). The most widely used tools are the LEED, BREEAM, CASBEE and SBTool, according to Bernardi et al. (2017). Therefore, to minimise the discrepancies and enhance applicability and more reliable results, some building tools can be integrated. Such integration will promote broader spatial usability at the regional or continental level. It will also enhance the achievement of sustainability in building as more attributes will be considered. Additionally, the use of BIM with sustainable building assessment tools has been argued to give better results (Carvalho et al., 2019). Active stakeholders' participation is key to achieving the desired integration in the sustainability assessment of buildings (Roostaie et al., 2019).

\section{Conclusion}

The construction sector, one of the significant users of energy and natural resources, is estimated to use nearly $40 \%$ of the total raw-material inflow to the global economy each year. As a result of this, the construction sector is a crucial contributor to environmental pollution and poses challenges in meeting sustainable development goals. Hence, the environmental assessment tools of the building were reviewed, which shows that the exercise is worthwhile as it offers several benefits to the society and environment. Its introduction has resulted in increased pre-contract design work which may be due to the requirements of meeting the energy dimension in the BREEAM model (Parker, 2012). The model has created awareness among the stakeholders and has achieved high levels of success. Over 1000 buildings have been assessed in the UK, and over 1800 individuals as assessors (Parker, 2012). Thus, it creates jobs in addition to protecting the environment. Mitigation measures are integrated into the certification. It is cost-effective, especially in the long run and more environmentally friendly, unlike the conventional ones (Roodman et al., 1995).

Moreover, assessment cost can be reduced by subsidising the cost of acquiring green building materials, and the exercise made a continuous one like EIA and backed by 
legislation. That is, monitoring should be a part of the BREEAM assessment to routinely check if developers keep the buildings to set standards, especially in the post-construction period. There is a close affinity between BREEAM and EIA. Both pursue the same goal of promoting and enhancing environmental quality. However, in EIA, the emphasis is on mitigating impacts, whereas, in BREEAM, the emphasis is on maximising benefits. Furthermore, EIA has statutory backing. That is, legislation drives EIA, while in BREEAM, certification is voluntary. Nevertheless, both have measures that can be fed in to achieve similar goals (Jacobs, 2017).

\section{References}

Ahmad, T., Thaheem, M. J. 2018. Economic sustainability assessment of residential buildings: A dedicated assessment framework and implications for BIM, Sustainable Cities and Society, 38: 476-491.

Al-Qawasmi, J., Asif, M., El Fattah, A. A., Babsail, M. O. 2019. Water efficiency and management in sustainable building rating systems: Examining variation in criteria usage, Sustainability, 11(8): 2416.

Al-Qawasmi, J., 2019. Examining indicators coverage in a sample of sustainable building assessment systems. Architectural Engineering and Design Management, 15(2): 101-120.

Al-Sakkaf, A., Zayed, T., Bagchi, A. 2020. A sustainability based framework for evaluating the heritage buildings. International Journal of Energy Optimization and Engineering (IJEOE), 9(2): 49-73.

Atanda, J. O., Öztürk, A., 2020. Social criteria of sustainable development in relation to green building assessment tools, Environment, Development and Sustainability, 22(1): 61-87.

Berardi, U., 2012. Sustainability assessment in the construction sector: rating systems and rated buildings, Sustainable Development, 20(6): 411-424.

Bernardi, E., Carlucci, S., Cornaro, C., Bohne, R. A. 2017. An analysis of the most adopted rating systems for assessing the environmental impact of buildings, Sustainability, 9(7): 1226.

Bouwer, M., De Jong, K., Jonk, M., Berman, T., Bersani, R. et al. 2005. Green Public Procurement In Europe 2005-Status Overview, Virage Milieu \& Management By, Haarlem, The Netherlands.

Braulio-Gonzalo, M., Bovea, M. D. 2020. Relationship between green public procurement criteria and sustainability assessment tools applied to office buildings, Environmental Impact Assessment Review, 81: 106310.

Calquin, D. A. L. 2017. August. Automated building data exchange between BIM and BPS supporting building environmental assessment methods (BEAM). In Proceedings of the 15th IBPSA Conference San Francisco, CA, USA. pp. 1329-1333.

Carvalho, J. P., Bragança, L., Mateus, R. 2019. Optimising building sustainability assessment using BIM, Automation in Construction, 102: 170-182.

Cole, R. J. 1998. Emerging trends in building environmental assessment methods, Building Research \& Information, 26: 3-16.

Grace, M. 2000. Breeam-A practical method for assessing the sustainability of buildings for the new millennium. Proceedings: International Conference Sustainable Building 2000: 2225 . 
Haapio, A., Viitaniemi, P. 2008. A critical review of building environmental assessment tools, Environmental Impact Assessment Review, 28: 469-482.

Haapio, A., 2012. Towards sustainable urban communities, Environmental Impact Assessment Review, 32(1): 165-169.

Hui, E. C., Tse, C. K., Yu, K. H. 2017. The effect of BEAM Plus certification on property price in Hong Kong. International Journal of Strategic Property Management, 21(4): 384400.

Ilhan, B., Yaman, H. 2016. Green building assessment tool (GBAT) for integrated BIM-based design decisions, Automation in Construction, 70: 26-37.

Jacobs. 2017. Seminar delivered by the company to ea students in the school of geography, The University Of Leeds, 25 April 2017.

Kajikawa, Y., Inoue, T., Goh, T. N. 2011. Analysis of building environment assessment frameworks and their implications for sustainability indicators, Sustainability Science, 6: 233-246.

Karaca, F., Guney, M., Kumisbek, A., Kaskina, D. and Tokbolat, S. 2020. A new stakeholder opinion-based rapid sustainability assessment method (RSAM) for existing residential buildings, Sustainable Cities and Society, 60: 102-155.

Kawakubo, S., Murakami, S., Ikaga, T. and Asami, Y. 2018. Sustainability assessment of cities: SDGs and GHG emissions, Building Research \& Information, 46(5): 528-539.

Lee, W. 2013. A comprehensive review of metrics of building environmental assessment schemes, Energy And Buildings, 62: 403-413.

Li, Y., Chen, X., Wang, X., Xu, Y. and Chen, P.H. 2017. A review of studies on green building assessment methods by comparative analysis, Energy and Buildings, 146: 152159.

Liu, T. Y., Chen, P. H., Chou, N. N., 2019. Comparison of assessment systems for green building and green civil infrastructure, Sustainability, 11(7): 2117.

Lowe, J., Watts, N. 2011. An evaluation of a breeam case study project, Sheffield Hallam University Built Environment Research Transactions, 3, $42-53$.

Madu, I. A., Nwankwo, C. F. 2020. Spatial pattern of climate change and farmer-herder conflict vulnerabilities in Nigeria, GeoJournal, 1-17.

Mahmoud, S., Zayed, T. and Fahmy, M. 2019. Development of sustainability assessment tool for existing buildings, Sustainable Cities and Society, 44: 99-119.

Mccrudden, C. 2004. Using public procurement to achieve social outcomes. Natural Resources Forum, Wiley Online Library, 257-267.

Nwankwo, C. F., Okafor, U. P. 2018. Impediments and desirability of complete ban on international movement of toxic waste, Open Political Science, 1(1): 131-135.

Raslanas, S., Kliukas, R. and Stasiukynas, A., 2016. Sustainability assessment for recreational buildings, Civil Engineering and Environmental Systems, 33(4): 286-312.

Rockström, J., Sachs, J. D., Öhman, M. C., Schmidt-Traub, G. 2013. Sustainable development and planetary boundaries. background research paper submitted to the high level panel on the post-2015 development agenda. Paris, New York: Sustainable Development Solutions Network.

Roodman, D. M., Lenssen, N. K., Peterson, J. A. 1995. A building revolution: how ecology and health concerns are transforming construction, Worldwatch Institute Washington, Dc.

Roostaie, S., Nawari, N., Kibert, C. J. 2019. Sustainability and resilience: A review of definitions, relationships, and their integration into a combined building assessment framework. Building and Environment, 154: 132-144.

Sadler, B. 2004. On evaluating the success of eia and sea. Assessing Impact: Handbook Of Eia And Sea Follow-Up, 248-285. 
Solla, M., Ismail, L.H. and Yunus, R. 2016. Investigation on the potential of integrating BIM into green building assessment tools. ARPN Journal of Engineering and Applied Sciences, 11(4), 2412-2418.

Stender, M., Walter, A. 2019. The role of social sustainability in building assessment, Building Research \& Information, 47(5): 598-610.

Tam, V. W., Tam, C., Zeng, S., Chan, K. 2006. Environmental performance measurement indicators in construction, Building And Environment, 41: 164-173.

Therivel, R. 2012. Strategic Environmental Assessment In Action, Routledge.

Uttam, K. 2014. Seeking sustainability in the construction sector: opportunities within impact assessment and sustainable public procurement, Kth Royal Institute Of Technology.

Williams, S., Chambers, T., Hills, S., Dowson, F. 2007. Buying A better world: sustainable public procurement. 2007. Forum For The Future. 